\title{
Sobrevivencia y rol de la via extrinseca e intrinseca de la apoptosis en macrofafos incubados con formocresol y sulfato ferrico
}

Tesis para optar al título de Doctor en Odontología

Dra. Cardoso María Lorena

Autora

Dra. Nora Cristina Brandan

Directora

Dra. Gabriela Victoria Quinteros de Lucas

Co-Directora

\section{Resumen}

Los medicamentos utilizados frecuentemente en los tratamientos pulpares de piezas dentarias primarias pueden entrar en contacto con la pulpa y por su capacidad de difusión alcanzar los tejidos periapicales. Tanto el tejido pulpar como el periodontal inflamado, muestran una gran cantidad de células con un predominio de macrófagos. La evaluación de los aspectos toxicológicos a través de los sistemas de cultivos celulares proporciona un medio conveniente, controlable y repetible. El objetivo de este trabajo fue evaluar in vitro en macrófagos peritoneales murinos ( $\mathrm{pM} \phi$ ) expuestos a FC, y SF, los patrones de muerte celular (apoptosis y necrosis), correlacionando estos resultados con las proteínas involucradas en estos procesos como Bax, Fas, de shock térmico (HSP60) y la sobrevivencia mediada por la expresión de la proteína antiapoptotica $\mathrm{Bcl}-\mathrm{X}_{\mathrm{L}}$.

Este estudio se realizo con ensayos de discriminación de células inflamatorias obtenidas de lavajes peritoneales murinos, en su mayoría células macrofágicas, las que fueron distribuidas en tres grupos experimentales: control, FC (al I\%) y SF ( $1 \%)$, incubándose en tiempos pre determinados $(2,4,6,12,18$ y 24 horas). Para cada tiempo de cultivo y en cada grupo experimental se determino la viabilidad celular mediante ensayo de Trypan Blue, la morfología celular a través de microscopia electrónica de barrido, y los índices de apoptosis y necrosis a través de técnicas de tinción de May-Grumwald-Giemsa 
REVISTA FACULTAD DE ODONTOLOGÍA

ISSN No 1668-7280 - Vol. VIII № 1 - 2015

54 y fluorescencia. Simultáneamente, se midió a través de western blotting, la expresión de proteínas relacionadas a muerte celular, -Fas, Bax-, estrés celular -HSP60- y sobrevivencia - $B c l-x_{L}-$. Los resultados relacionados con la viabilidad de pM $\phi$ en los grupos expuestos al FC, demostraron que la misma decrece entre las 4 y 12 horas de incubación, retornando a valores similares a los observados en las células control a las 18 horas de cultivo. Esta particular respuesta puede ser atribuida al pool viable de $\mathrm{pM} \phi$ que permanece disponible gracias a la expresión de la proteína anti-apoptótica $B c l-x_{L}$, relacionada con la sobrevivencia y viabilidad de las células. Contrariamente, en los grupos expuestos a SF se observo una disminución de la viabilidad entre las 12 y 24 horas de incubación, observándose la coexistencia de ambos procesos de muerte celular -apoptosis y necrosis- y la expresión de $B c l-x_{L}$ a las 24 horas de incubación inclusive. Relacionando estos últimos datos con los observados en los índices de apoptosis y necrosis podemos inferir que a pesar de la sobrexpresión de $\mathrm{Bcl}-\mathrm{x}_{\mathrm{L}}$ (proteína involucrada en la sobrevivencia celular), los programas de muerte celular no pueden suprimirse una vez activados.

Estos resultados demuestran comparativamente con el control que en $\mathrm{pM} \phi$ expuestos a FC, se activan dos vías diferentes, una que inicia la apoptosis dependiendo de la expresión de Bax (2-6 hs) y el otro que favorece la necrosis (4- 18 hs) relacionado con la activación del receptor Fas y la sobrexpresión de las HSP60. Para los grupos incubados con SF se evidencio una iniciación tardía de los procesos de apoptosis ( $12 \mathrm{hs}$ ), estrechamente relacionada a la vía extrínseca a través de la sobrexpresion de Fas y potenciada por la vía intrínseca a través de la sobrexpresión de Bax, observándose la coexistencia de ambos procesos de muerte celular -apoptosis y necrosis- a las 24 horas de incubación.

Los resultados nos permiten inferir que el efecto de necrosis del FC en células $\mathrm{PM} \phi$ es agudo y muy acentuado en las primeras horas en que la droga entra en contacto, y luego de 6 horas su acción citotóxica disminuye. Esta toxicidad de corto tiempo (acción autolimitante) puede inducir respuestas inflamatorias in vivo más leves en el área periapical, lo que causaría menos síntomas post tratamiento, como inflamación y dolor.

Por su parte, el SF induce procesos de muerte celular tardíamente en células $\mathrm{pM} \phi$, siendo mas elevado el mecanismo de apoptosis que el de necrosis incrementándose este efecto proporcionalmente al tiempo en que la droga permanece en contacto.

El presente estudio contribuye al conocimiento del complejo fenómeno que se produce cuando estas drogas entran en contacto con los tejidos, específicamente con las células inflamatorias, y si bien todas las drogas producen efectos adversos, el grado de citotoxicidad y la duración del efecto irritante son indicadores del tipo de daño que estos pueden producir en los tejidos periapicales. 